\begin{tabular}{lcl}
\hline INESEG \\
$\begin{array}{c}\text { INTERNATIONAL } \\
\text { ENGINEERING, } \\
\text { SCIENCE AND } \\
\text { EDUCATION GROUP }\end{array}$ & Middle East Journal of Science \\
https://dergipark.org.tr/mejs
\end{tabular}

Research Article

\title{
PROTECTIVE BEHAVIOR AGAINST CORROSION OF POLY(N-METHYLANILINE) COATINGS ELECTROSYNTHESIZED ON STAINLESS STEEL SURFACE FROM SULFURIC ACID CONTAINING MONOMER SOLUTION*
}

\author{
Zeynel Doğruyol $^{1 *}$ (1) Aziz Yă̆an ${ }^{2}$ (1) \\ ${ }^{1}$ D. H. M. İ. Mardin Airport, Turkey \\ ${ }^{2}$ Dicle University, Faculty of Education, Turkey \\ Corresponding author: zeyneldogruyol@gmail.com
}

\begin{abstract}
Thanks to their outstanding optical and electrical properties, potential polymers are one of the materials with the highest potential use in technological applications. In this study Poly(Nmethylaniline) coated stainless steel disc electrodes were obtained with $N$-methylaniline containing sulfuric acid solutions using constant potential, constant current and potentiodynamic techniques by electrodeposition. Corrosion behavior of polymer coated electrodes were investigated by direct current (DC) polarization technique and linear anodic cyclic voltammetry in different aqueous ( $\mathrm{NaCl}$ and $\mathrm{HCl}$ ) solutions. Electrochemical techniques branching test results showed that the electroactive PNMA coating can be used as a protective coating against rust for stainless steel. It was demonstrated that $\mathrm{N}$ methylaniline aniline and pyrrole with an aqueous solution of $\mathrm{H}_{2} \mathrm{SO}_{4}$ as the electrolyte can also show positive copolymers and various coatings.
\end{abstract}

Keywords: Electropolymerization, Poly(N-methylaniline), Corrosion, DC polarization.

*This work was presented at the $5^{\text {th }}$ International Engineering and Natural Sciences Conference, November 5-6, 2020, Dicle University, Diyarbakır, TURKEY

Received: December 1, 2020

Accepted: December 28, 2020

\section{Introduction}

Corrosion has become one of the most serious problems of our day due to its economic, safety, and environmental effects. If protective coatings are used on metals or alloys exposed to corrosion, the world economy can be saved from the serious effects of corrosion losses. The use of protective coatings will reduce problems caused by corrosion and greatly increase the effective life of most metal-containing machines.

As a result of the studies, it has been determined that electroactive conductive polymers can be used as protective coatings since traditional methods used in protecting metals with oxidizing properties against corrosion can cause serious environmental problems. In particular, the electrodeposition of conductive polymers to common metals $(\mathrm{Zn}, \mathrm{Fe}, \mathrm{Al})$ on the surface has been an important subject of study in recent years (Deberry 1985).

Conductive polymers not only act as a protective coating on metals in a corrosive environment but also prevent corrosive ions from reaching the metal surface due to their electroactivity when exposed to a corrosive environment for a long time (Sazou 1997). During electropolymerization, a more stable 
passive oxide layer occurs at the electrode surface polymer interface compared to those obtained in the electrolysis solution containing the electrolyte with the monomer ( $\mathrm{Su}$ 2000). For this purpose, conductive polymers such as PANI-Fe $\mathrm{O}_{3}$ (Sumi 2020), polypyrrole (Ppy) (Mortazavi), PTh (Ai 2014), polyindol (Paved 2013) have been investigated due to their high environmental stability, non-toxic properties, and easily adjustable conductive oxidation state, simple and economical production methods.

In the study achieved by Döşlü et al., the protection efficiency of polyindole film on stainless steel was increased with titanium dioxide pre-coating. Characterization of the coatings was provided by nuclear magnetic resonance and Fourier transform infrared spectra. The surface morphology of electrodes was monitored by scanning electron microscopy. Corrosion performance was examined in $\% 3.5 \mathrm{NaCl}$ solution by electrochemical impedance spectroscopy and potentiodynamic measurements. Quantum calculations were made and theoretical parameters were determined. The results showed that there is a relationship between experimental and theoretical parameters. High protection efficiency against corrosion was observed on the steel surface by forming a protective polyindole top-coated titanium dioxide film (Döşlü et al 2013).

The PANI- $\mathrm{Fe}_{2} \mathrm{O}_{3}$ composite synthesized in the study by Sumi et al. was incorporated into a commercial alkyd resin and an effective anticorrosive coating for mild steel was developed. Both composite and fabricated alkyd resin coatings have been systematically characterized using FTIR, XRD, SEM, TEM, XPS, TGA, OSP, SKPM, and EDS. Corrosion-resistant properties of nanocomposite coatings were evaluated by potentiodynamic polarization, impedance spectroscopy, and long-term open circuit potential measurements at $\% 3.5 \mathrm{NaCl}$ and $1 \mathrm{M} \mathrm{HCl}$. The much-improved corrosion resistance of the coating containing PANI-Fe2O3 has been associated with better barrier performance and passivation protection offered. The higher corrosion resistance observed in an acidic environment was explained by the complementary cathodic reaction of conductive emeraldin-PANI to non-conductive leuko-PANI. The manufacturing method provided may be useful for the development of environmentally friendly anti-corrosion "conductive polymer-metal oxide-alkyd resin" coatings (Sumi et al 2020).

In the study achieved by Mortazavi et al, polyethylene glycol (PEG) doped ammonium bifluoride doped Ppy and embedded Ppy coatings were deposited on AZ31 Mg alloy using cyclic voltammetry. The results of fluoride-nuclear magnetic resonance (F-NMR), thermal gravimetric analysis (TGA), and differential scanning calorimetry (DSC) showed that the fluoride additive in the polyethylene glycol molecule was applied. Corrosion performance of doped Ppy coatings was evaluated by electrochemical impedance spectroscopy (EIS) and potentiodynamic polarization techniques in $0.05 \mathrm{M} \mathrm{NaCl}$ solution. Field emission scanning electron microscopy (FESEM) and energy-dispersive $\mathrm{x}$-ray spectroscopy (EDS) showed that doped Ppy coatings have higher corrosion resistance than Ppy coating. The load transfer resistance of the doped Ppy coating was measured approximately 2 and 5 times higher than the undoped Ppy and Ppy coatings, respectively, which is associated with the synergistic behavior of fluoride with polyethylene glycol as well as its release into the anodic regions.

In the study conducted by Ai et al., A simple, no template method was successfully implemented to prepare polythiophene microspheres with uniform size and well spherical shape using anhydrous $\mathrm{FeCl}_{2}$ as catalyst and $\mathrm{H}_{2} \mathrm{O}_{2}$ as oxidant by one-pot chemical oxidation polymerization. The structure and morphology of polythiophene nanoparticles have been characterized by IR, SEM, and TEM. Polythiophene nanostructures exhibited good microsphere morphology with a very narrow particle size distribution. By fine-tuning the reaction conditions, polythiophene in different sizes and nanostructures can be obtained. The corrosion protection property of coatings containing polythiophene microsphere 
on soft steel was investigated by electrochemical impedance spectroscopy (EIS) technique in \%3.5 $\mathrm{NaCl}$ aqueous solution by weight. The results showed that coatings containing water-based polythiophene microspheres (PTh content, \% 0.6 by weight) can provide high protection because impedance values remained higher than $1 \times 106 \Omega \mathrm{cm}^{2}$ after 360 hours. All results are comparable to pure water-based epoxy coatings on mild steel (Ai et al 2014).

PPy deposits were successfully electropolymerized potentiodynamically on a pre-passivated $\mathrm{Fe}$ electrode in an aqueous solution containing monomer and oxalic acid. Electropolymerization of PPy was carried out between $0.3 \mathrm{~V}$ and $0.8 \mathrm{~V}$ versus $\mathrm{SCE}$ with a scanning rate of $20 \mathrm{mV} / \mathrm{s}$. Electrochemical properties of PPy coated Fe electrode was determined using cyclic voltammetry, galvanostatic chargedischarge cycle, and electrochemical impedance spectroscopy. The maximum specific capacitance of PPy coated Fe electrode is $2280 \mathrm{~F} / \mathrm{g}$. This demonstrates the applicability of the PPy coated Fe electrode. However, the PPy coated Fe system behaved like PAni and showed high capacitance, not like Ppy. Using the cyclic voltammetry technique from aqueous oxalic, $0.2 \mathrm{~V}$ and $1.1 \mathrm{~V}$ acid electrolyte solution were obtained against SCE with a scanning speed of $20 \mathrm{mV} / \mathrm{s}$. The properties of adhesive and electroactive PNMA coatings have been successfully investigated using the cyclic voltammetry technique. On the other hand, electrochemical impedance spectroscopy (EIS) was used to examine the long-term corrosion performance of PANI and PNMA coated electrodes separately in $0.5 \mathrm{M} \mathrm{NaCl}$ and $0.5 \mathrm{M} \mathrm{HCl}$ solutions. EIS measurement results showed that PANI and PNMA coatings improve protection for SS in neutral and acidic corrosive solutions. In addition, PANI and PNMA coatings were able to offer protection to SS electrodes for a longer immersion time in $\mathrm{NaCl}$ solution compared to $\mathrm{HCl}$. After immersion in $\mathrm{NaCl}$ for 168 hours, the PANI coating of the steel was insufficient to prevent corrosion, while the PNMA coating lost its protective properties after 240 hours (Yagan 2019).

In the study conducted by Yagan et al., Poly (N-ethylaniline) (PNEA) coatings were deposited on $\mathrm{Fe}$ and Pt-disk electrodes by potentiodynamic synthesis technique. The coating was carried out using an aqueous solution of oxalic acid containing the monomer of N-ethylaniline. PNEA polymer growth was found to be much less than on the Pt surface. On the surface of Fe. PNEA coatings have been characterized both electrochemically and spectroscopically. Linear anodic potentiodynamic polarization, Tafel test, and electrochemical impedance spectroscopy techniques were used in the corrosion protection coating $0.5 \mathrm{M} \mathrm{H}_{2} \mathrm{SO}_{4}, 0.1 \mathrm{M} \mathrm{HCl}$, and $0.5 \mathrm{M} \mathrm{NaCl}$ solutions of PNEA. For comparison, PANI was also used on the Fe surface by potentiodynamic synthesis technique. The presence of PNEA and PANI coatings on the Fe electrode limits the dissolution potential range with respect to the linear anode. Potentiodynamic polarization curves obtained in $0.5 \mathrm{M} \mathrm{H}_{2} \mathrm{SO}_{4}$, the maximum dissolution current density values for PNEA and PANI coated Fe electrodes were $10.7 \mathrm{~mA} \mathrm{~cm} 2$ and $11.6 \mathrm{~mA} \mathrm{~cm}$, respectively. These current density values were found to be significantly lower compared to bare. electrode $(41.8 \mathrm{~mA} \mathrm{~cm})^{2}$. Tafel test results have shown that the PNEA coating exhibits significant corrosion protection properties in the $\mathrm{NaCl}$ environment. That of the $\mathrm{HCl}$ medium. Longterm impedance measurements of PNEA coated and uncoated electrodes in $\mathrm{NaCl}$ and $\mathrm{HCl}$ solutions, corrosion protection properties of PNEA coating in $\mathrm{NaCl}$ environment $\left(135.02 \Omega \mathrm{cm}^{2} \mathrm{R}_{\mathrm{ct}}\right.$ value after 196 hours) compared to significantly higher $\mathrm{HCl}$ environment $\left(20.30 \Omega \mathrm{cm}^{2} \mathrm{R}_{\mathrm{ct}}\right.$ value after 48 hours) It has been determined that the corrosion results obtained independently, electrochemical methods in three different corrosive environments are in full harmony with each other (Yagan et al 2007).

In this study, we investigated the effect of PNMA on stainless steel electrodes in aqueous sulfuric acid solutions of electrosynthesis conditions. The conductivity of polymer layers against corrosion on 
the alloyed surfaces was examined and compared in sulfuric acid solutions, linear potentiodynamic polarization, DC polarization test technique, and $\mathrm{NaCl}, \mathrm{HCl}$, and $\mathrm{H}_{2} \mathrm{SO}_{4}$ solutions.

\section{Methods}

Electrochemically prepared coatings were immersed in distilled water to remove the adsorbed electrolyte monomer and soluble oligomers formed during the electroplating process of the coating and then dried at room temperature.

\subsection{Linear anodic potentiodynamic polarization method}

Anti-corrosion control of polymer-coated and uncoated electrodes was performed in $0.5 \mathrm{M}$ $\mathrm{H}_{2} \mathrm{SO}_{4}$ aqueous solutions at $10 \mathrm{mv} / \mathrm{s}$ with $1 \backslash 2$ cycles with potentiodynamic scanning method in the potential region between $-0.3 \mathrm{~V}$ and $+0.9 \mathrm{~V}$ and SCE.

\subsection{Polarization}

It is a potentiodynamic corrosion test method. DC polarization tests were performed under continuously mixed conditions with a capillary bridge containing a thin terminal block to minimize ohmic resistance. Anodic and cathodic polarization curves were recorded by varying the electrode potential between $-650 \mathrm{mV}+250 \mathrm{mV}$ with a constant sweep rate of $1 \mathrm{mV} / \mathrm{s}$ in an unventilated $0.5 \mathrm{M}$ $\mathrm{NaCl}, 0.5 \mathrm{M} \mathrm{HCl}$.

\section{Results}

The behavior of uncoated and PNMA coated electrodes when a $0.5 \mathrm{~V}$ vs SCE constant potential is applied in a corrosive $0.5 \mathrm{M} \mathrm{HCl}$ solution is given in Figure 1. The solid line curve shows that stainless steel dissolves strongly at this potential. When the same electrode is coated with PNMA by electrosynthesis and this surface is exposed to a constant potential of $0.5 \mathrm{~V}$, it is seen that the behavior changes completely. First of all, there is no dissolution observed in the uncoated electrode. This indicates that the layer on the surface protects the stainless steel surface. This experiment result given a strong indication that the PNMA coating can provide effective protection against corrosion.

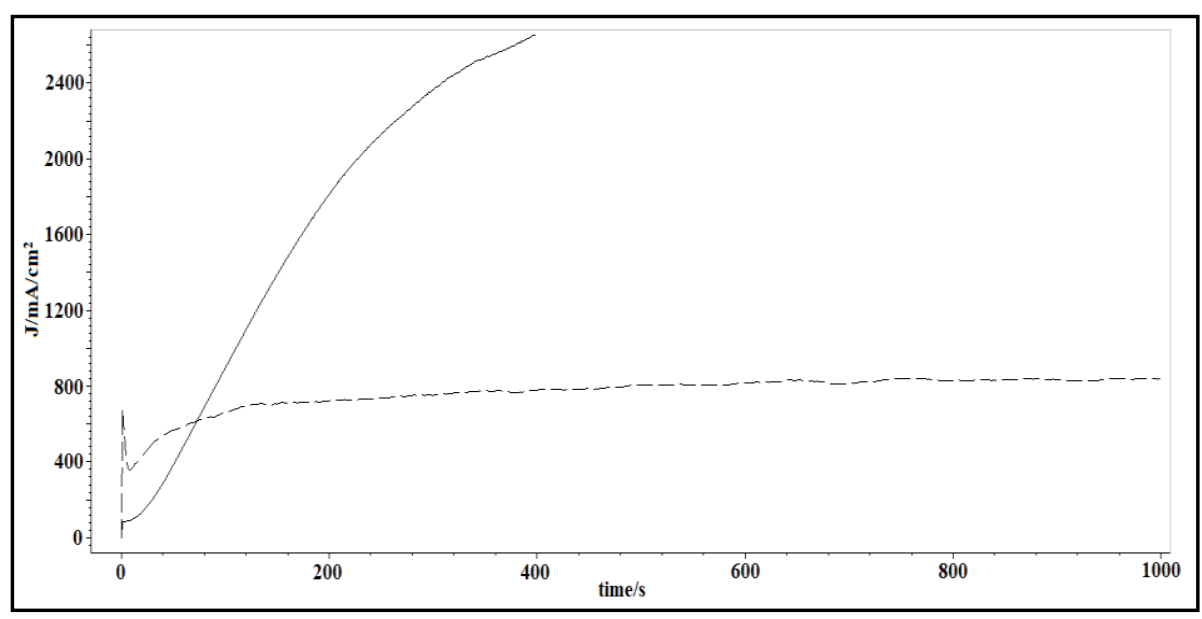

Figure 1. The behavior of the polymer when a $0.5 \mathrm{~V}$ constant potential is applied to the uncoated and PNMA coated electrodes in a corrosive $0.5 \mathrm{M} \mathrm{HCl}$ solution. 
Figure 2. shows the behavior of the polymer when a $0.5 \mathrm{~V}$ constant potential is applied to the uncoated and PNMA coated electrodes in a corrosive $0.5 \mathrm{M} \mathrm{NaCl}$ solution. The solid line curve shows that stainless steel dissolves strongly at this potential. When the same electrode is coated with PNMA with electrosynthesis and this surface is exposed to a constant potential of $0.5 \mathrm{~V}$, it is seen that the behavior changes completely. First of all, there is no dissolution observed in the uncoated electrode. This indicates that the layer on the surface protects the stainless steel surface. This experiment gives a strong indication that the PNMA coating can provide effective protection against corrosion.

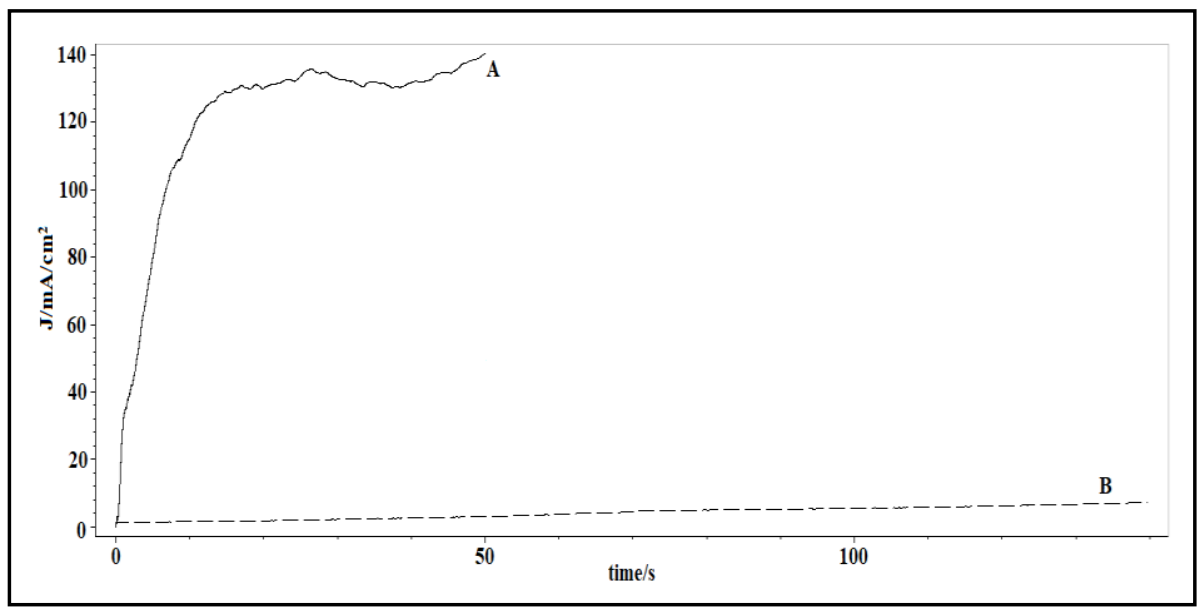

Figure 2. The behavior of the polymer when a $0.5 \mathrm{~V}$ constant potential is applied to the uncoated and PNMA coated electrodes in a corrosive $0.5 \mathrm{M} \mathrm{NaCl}$ solution.

Figure 3 shows the Tafel curves obtained in $0.5 \mathrm{M} \mathrm{NaCl}$ solution of uncoated PNMA coated electrodes obtained at $10 \mathrm{mv} / \mathrm{s}$ scanning speed. The increasing of the coated electrode to the positive potential and the decrease in the current values, especially on the anodic side, are indicators of the protection of the coating

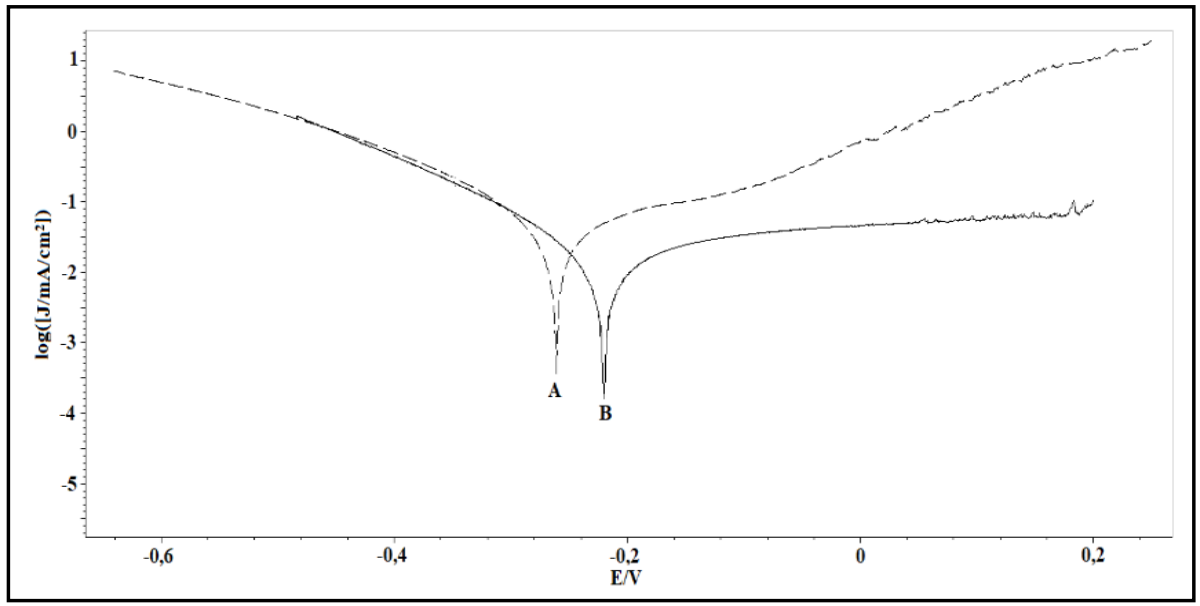

Figure 3.Tafel curves obtained in $0.5 \mathrm{M} \mathrm{NaCl}$ solution of PNMA coated electrodes with uncoated and $10 \mathrm{mv} / \mathrm{s}$ scanning speed (A: Uncoated; B: Coated) 
Figure 4 shows the Tafel curves obtained in $0.5 \mathrm{M} \mathrm{HCl}$ solution of PNMA coated electrodes obtained at a scanning speed of $10 \mathrm{mv} / \mathrm{s}$ and uncoated. The attraction of the coated electrode to the positive potential and the decrease in the current values, especially on the anodic side, are indicators of the protection of the coating. When the behavior of coated electrodes in B and C curves is compared against uncoated electrodes, it is clear that PNMA coating protects better in $\mathrm{HCl}$ than $\mathrm{NaCl}$; The corrosion current exhibited by the coated electrode has shifted considerably to noble potentials.

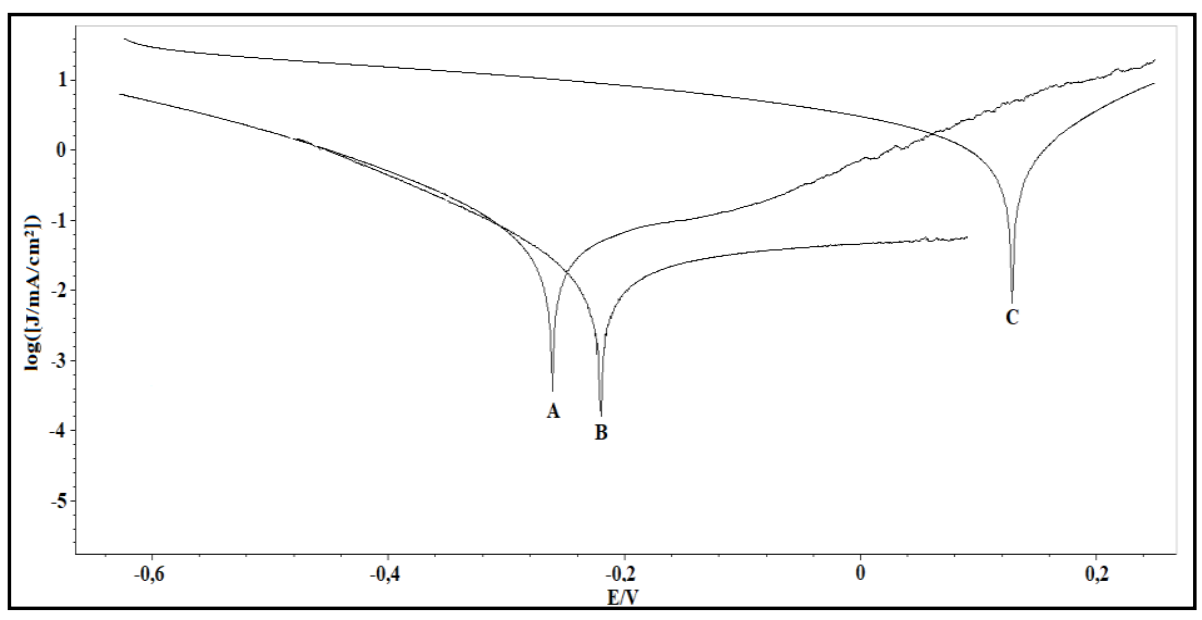

Figure 4. Tafel curves obtained in $0.5 \mathrm{M} \mathrm{HCl}$ and $0.5 \mathrm{M} \mathrm{NaCl}$ solution of PNMA coated electrodes obtained at $10 \mathrm{mv} / \mathrm{s}$ scanning speed without coating (C: $\mathrm{HCl}$ environment)

\section{Discussion}

The characterization process for PNMA coated steel electrodes was carried out by electrochemical technique and the polymer was obtained. The extent to which the PNMA coated electrode surfaces obtained protects the steel against corrosion was determined by linear chronoamperometry, potentiodynamic polarization, and the Tafel method. According to corrosion test results, the stainless steel of the electroactive PNMA coating can be used as corrosion protection and coating.

The electrolyte can be an aqueous $\mathrm{H}_{2} \mathrm{SO}_{4}$ solution. $\mathrm{N}$-methylaniline copolymers with aniline and pyrrole, and various coatings.

The compliance to the Research and Publication Ethics: This study was carried out in accordance with the rules of research and publication ethics.

\section{Acknowledgments}

The authors are grateful to the Dicle University Research Fund (DUBAP, Project No ZGEF.17.020) for their financial support. 


\section{References}

[1] Ai, L., Liu, L., Zhang, X., Ouyang, X., Ge, Z., ' A facile and template-free method for preparation of polythiophene microspheres and their dispersion for waterborne corrosion protection coatings" Synthetic metals Vol (191), pp.41- 46, 2014.

[2] Döşlü, S., Mert, B., Yazıcı, B., 'Polyindole top coat on $\mathrm{TiO}_{2}$ sol-gel films for corrosion protection of steel"' Corrosion science Vol (66), pp.51-58, 2013.

[3] Deberry, W., J. Electrochemical Society. Vol (132), pp.1022, 1985.

[4] Mortazavi, S., Yeganeh, M., Etamed, A., Saremi, M., ' Corrosion behavior of polypyrrole (Ppy) coating modified by polyethylene glycol (PEG) doped ammonium bifluoride on AZ31 magnesium alloy"' Progress in Organic Coatings Vol (134), pp.22-32, 2019.

[5] Sazou, D., Georgolios, C., " Formation of conducting polyaniline coatings on iron surfaces by electropolymerization of aniline in aqueous solutions"' Journal of Electroanalytical Chemistry Vol (429) pp.81-93, 1997.

[6] Sumi, V., Arunima, S., Deepa, M., Sha, M., Riyas, A., Meera, M., Saji, V., Shibli, S., "' PANI$\mathrm{Fe}_{2} \mathrm{O}_{3}$ composite for enhancement of active life of alkyd resin coating for corrosion protection of steel"' Materials Chemistry and Physics Vol (247), pp.122881, 2020.

[7] Yağan, A., Pekmez, N., Yıldız, A.,' Investigation of protective effect of poly(N-ethylaniline) coatings on iron in various corrosive solutions"' Surface \& Coatings Technology Vol (201) pp.7339$7345,2007$.

[8] Yağan, A., ' Investigation of Polypyrrole-Based Iron Electrodes as Supercapacitors'” International Journal of electrochemical science Vol (14), pp. 3978-3985, 2019. 